\title{
Building a Smart Interactive Kiosk for Tourist Assistance
}

\author{
Hanane Amessafi ${ }^{1}$, Reda Jourani ${ }^{2}$, Adil Echchelh ${ }^{1}$, and Houssain Oulad Yakhlef ${ }^{3}$ \\ ${ }^{1}$ Laboratory of electrical engineering and energetic systems \\ Faculty of Sciences, Kenitra, Ibn Tofail University, Kenitra, Morocco \\ ${ }^{2}$ Information Systems Engineering Group \\ Polydisciplinary Faculty of Tétouan, AbdelMalek Essaâdi University, Tétouan, Morocco \\ ${ }^{3}$ Modelling and information theory Group \\ Polydisciplinary Faculty of Tétouan, AbdelMalek Essaâdi University, Tétouan, Morocco \\ hanane.amessafi@gmail.com, reda.jourani@yahoo.fr, adilechel@gmail.com, houlad10@gmail.com
}

\begin{abstract}
The tourism sector in morocco is increasing rapidly, is well developed, with a strong tourist industry focused on the country's coast, culture, and history. Morocco is the most politically stable countrie in North Africa, which has allowed tourism to develop. There are some tourist attractions spread over a wide geographical area, which are only visited by a few people at specific times of the year. Additionally, having human tourist guides everywhere and speaking different languages is unfeasible. This work deals with the build of a smart interactive kiosk for tourist assistance. In order to do this, it is necessary to start with an Automatic Language Recognition to recognize the language used by the tourist, then extracting keywords from what the tourist said by using Automatic Speech Recognition techniques among others, and finally the system analyses and ansers to the tourist query by suggesting a set of related informations.
\end{abstract}

Keywords- Automatic Language Recognition, Automatic Speech Recognition, keyword extraction, question answering, Gaussian Mixture models, tourism

\section{Introduction}

In order to offer an attractive service for tourists visiting the kingdom of Morocco, we aim to build smart interactive kiosks for tourist assistance. These kiosks try to help tourists to find points of interest. Tourism is one of the most effective money-moving mechanisms, redistributing wealth, and promoting local economies. It brings income into a community that would otherwise not be earned[1]

Information systems are always dynamic, so learning adapts to new models of functioning by focusing first on automatic speech recognition while exploiting the news and the latest kinds of technologies, by analyzing the keywords from what the tourist said.

A recognition system includes several components:

A parameter extraction module, a matching block, a module for normalizing the match scores and a decision module. 


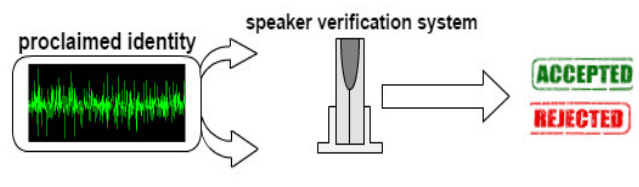

Fig 19 of a speaker verification system

Innovation consists in developing a multidisciplinary approach, bordering on the sciences of engineering and the sciences of analysis and treatment, favoring the interactions of the tourist with his need, based on field study and modelling. We will describe social-technical systems, in other words, the interdisciplinary methods of different problems, text comprehension, analysis of the blogosphere or social networks as well as artificial life and robotics: artificial learning that can be Endowing autonomous systems, which are inspired by natural behaviors without forgetting the integrative neurosciences: brain computing, perceptual-motor modelling ... which focus on the reactions of the subjects and the learning within the modelling of the action.

Professionals in this field confirm that $90 \%$ of the knowledge are stored in the heads, while the $10 \%$ are recorded in books and computers, the latter can search, store and process knowledge, but the importance is in the level of knowledge transfer. Much information and knowledge is on the web, but the manipulation of this knowledge is not well developed. Artificial Intelligence has its role to play.

The expert system avoids having to write new programs to reinject the information: thanks to its acquisition module, new data can be incorporated during use. It is designed to help a user in a particular field to find the appropriate solution for his inquiry, and this, of course, in the current state of specialised knowledge.

In this communication, we will describe two fundamental points: first, the questioning of "behaviorism", and secondly, the possibility of constructing models integrating data from neurosciences and cognitive psychology by using simulations and modeling of information technology.

The paper is organized as follows. After an overview on Automatic Language Recognition in section 2, we describe our Methodology in section 3. The experimental results and their discussions are then presented in section 4

\section{Maintaining the Expert System and Automatic Language Recognition}

The elaboration of an expert system is based on an approach essentially borrowed from the humanities. Surely, there is no ready-made method to define the different strategies of the experts. But, generally, the designer seeks to draw three levels within the mass of knowledge. See the table below.

Table 1 Levels of Knowledge

\begin{tabular}{|l|l|l|}
\hline Structuring level & \multicolumn{1}{|c|}{ Conceptual level } & \multicolumn{1}{|c|}{ Cognitive level } \\
\hline $\begin{array}{l}\text { Touches algorithmic } \\
\text { procedures in the field of } \\
\text { multilingual systems for } \\
\text { automatic recognition of } \\
\text { the language }\end{array}$ & $\begin{array}{l}\text { Represents knowledge } \\
\text { in order to represent } \\
\text { the concepts usually } \\
\text { used by the specialist. }\end{array}$ & $\begin{array}{l}\text { Gathers a large amount of raw } \\
\text { knowledge related to the field of } \\
\text { touristic communication. }\end{array}$ \\
\hline
\end{tabular}


Hanane Amessafi, Reda Jourani, Adil Echchel, and Houssain Oulad Yakhlef. Building a Smart Interactive Kiosk for Tourist Assistance. Case of Information Systems Management of a Private Moroccan University. Transactions on Machine Learning and Artificial Intelligence, Vol 5 No 4 August (2017); p: 622-627

For a system of rules, it is estimated that by the help of interviews, we can generate a very limited number of rules per day.

The causes are as follows:

The engineer is not a specialist in the field of expertise, but must learn a minimum knowledge base to communicate with the expert. events.

The expert does not generally think in terms of broad principles but in terms of typical situations and classical

It is already difficult to develop a framework (notations) to express knowledge, even on paper.

To exceed the limits of the expert system it is necessary to:

Better model the reasoning.

Better model the field.

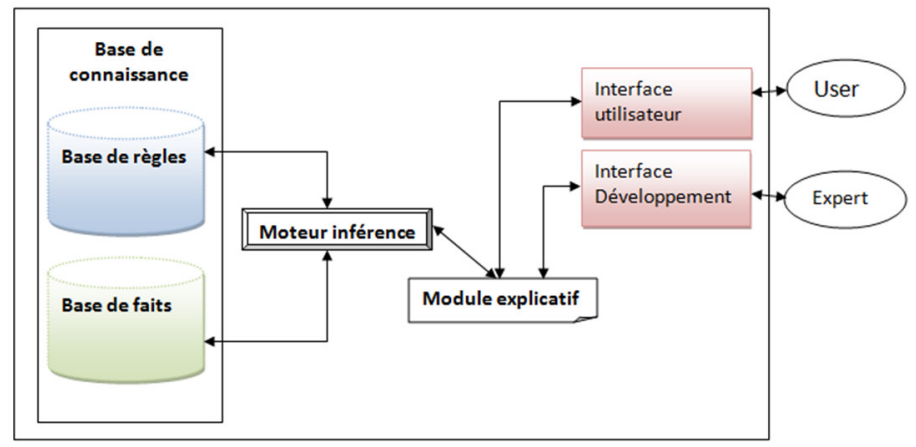

Figure 20 Design of an expert system

\section{Methodology}

Knowledge engineering would evoke techniques for manipulating knowledge on computer.

The effort is focused on:

Identification \& Acquisition :

Techniques \& Tools (documents, interviews ...)

Modeling \& Formalization: :

Language of modeling (field, task...)

Methodologies (KADS, KOD...)

Language of formal representation

Use

Surfing, inference, explanation...

Maintenance and management

Intervention of several disciplines

Artificial intelligence

Information systems \& documentaries

Software engineering 
Object Oriented Programming, Agent

Logic Programming

Human machine interfaces

Linguistics (Natural language, Terminology)

Logic (Formal logical reasoning)

Psychology

Ergonomics (HMI, user approach)

Pedagogy \& Teaching

Philosophy (with ontology)

Semiotics (Signs and Representations)

Sociology \& Anthropology (collective)

\section{Case Study and Results}

A statistical and scientific study has been carried out in order to promote our proposed solution in the field of tourism, in order to have and ensure a high level of communication between the tourist and the various receptionists. Here is what presents as results:

Taking into consideration the language of tourists can give more to the national economy.

Extracting keywords from what the tourist said.

Proposing responses to the tourist in relation to the extracted keywords.

So it is possible to say and to confirm that adaptive communication to the language of a tourist has an impact on the quality of service provided, the same method used by professionals "texts translated in several languages" does not meet their need, from wich comes the need for innovation of an INTELLIGENT MULTILINGUAL TOURIST ASSISTANCE SYSTEM.

Besides, the absence of 'face-to-face' communication remains an obstacle to the success of the Vision 2020 objectives. Therefore, the establishment of a communication and tourist assistance system will enable:

Meeting the needs of foreign tourists.

The establishment of a closer working environment to the reality.

\section{Conclusion}

The idea is to set up a computer terminal for tourists in order to provide them with certain information. Starting with an "automatic recognition of the language" that was used by the tourist, then extract keywords from what the tourist says ("automatic speech recognition"), and then propose responses to the tourist In relation to the extracted keywords. so our system is able to correctly inform tourists about interesting tourism topics and to propose other related information about any touristic issue.

For example, information will be given after saying the name of a city or a monument. Accommodation or catering sites will be indicated if the tourist says "hotel", "guest house", or "restaurant "..., we can treat the means of transport. 
Hanane Amessafi, Reda Jourani, Adil Echchel, and Houssain Oulad Yakhlef. Building a Smart Interactive Kiosk for Tourist Assistance. Case of Information Systems Management of a Private Moroccan University. Transactions on Machine Learning and Artificial Intelligence, Vol 5 No 4 August (2017); p: 622-627

Artificially intelligent agents, and other technological breakthroughs will help tourists to complete more transactions in less time and gather more relevant information about their destinations in real-time [1]

\section{REFERENCES}

[1] Garrido, P., Barrachina, J., Martinez, F., Seron, F., 2017. Smart tourist information points by combining agents, semantics and Al techniques. Comput. Sci. Inf. Syst. 14, 1-23. doi:10.2298/CSIS150410029G

[2] Towards a cognitive approach to human machine cooperation in dynamic situations : JEAN-MICHEL HOC

[3] DePaulo, J. Lindsay, B. Malone, L. Muhlenbruck, K. Charlton, and H. Cooper. 2003. Cues to deception. Psychological Bulletin, 129(1):74-118.

[4] Computer Simulation of Human Thinking : Allen Newell, Herbert A.Simon

[5] The Prospects for Psychological Science in Human-Computer Interaction : Allen Newell, Stuart K. Card

[6] Youcef B.C., Elemine Y.M., Islam B., Farid B. (2017) Speech Recognition System Based on OLLO French Corpus by Using MFCCs. In: Chadli M., Bououden S., Zelinka I. (eds) Recent Advances in Electrical Engineering and Control Applications. Lecture Notes in Electrical Engineering, vol 411. Springer, Cham

[7] Patel, K., Prasad, R.K.: Speech recognition and verification using MFCC \& VQ. Int. J. Emerg. Sci. Eng. (IJESE) 1(7) (2013). ISSN: 2319-6378

[8] Jourani, R. and Daoudi, K. and Andre-Obrecht, R. and 'Aboutajdine, D., "Large Margin Gaussian mixture models for speaker identification," in Proc. of Interspeech, 2010, pp. 1441-1444

[9] Achraf Ben Romdhane, Salma Jamoussi, Abdelmajid Ben Hamadou, Kamel Smaili Phrase-Based Language Model in Statistical Machine Translation ;International Journal of Computational Linguistics and Applications, Alexander Gelbukh, 2016 Journal articles

[10] Jourani, R., Daoudi, K., Andr'e-Obrecht, R., and Aboutajdine, D. (Online First). Discriminative speaker recognition using Large Margin GMM. Journal of Neural Computing \&Applications, doi :10.1007/s00521012-1079-y.

[11] Jourani, R., Daoudi, K., Andr'e-Obrecht, R., and Aboutajdine, D. (2011). Speaker verification using Large Margin GMM discriminative training. In Proc. of ICMCS, page 1-5

[12] M.E. Al-Ahdal and N.M. Tahir, "Review in sign language recognition systems," in ISCI'12 : IEEE Symposium

[13] A.K. Sahoo, G. S. Mishra, and K. K. Ravulakollu, "Sign language recognition : State of the art," ARPN Journal of Engineering and Applied Sciences, vol. 9,no. 2, pp. 116-134, 2014

[14] M. Koppel, S. Argamon, and A. Shimoni. 2002. Automatically categorizing written texts by author gender. Literary and Linguistic Computing, 4(17):401-412. 
Transactions on Machine Learning and Artificial Intelligence Vol 5 No 4, Aug 2017

[15] Karn ("Design And Evaluation Of A Phonological Phrase Parser For Spanish Text-To-Speech", Fourth International Conference on Spoken Language, Oct. 1996).*

[16] T.M. Derwing, M.J. Munro, and M. Carbonaro, "Does popular speech recognition software work with ESL speech?", TESOL Quarterly 34, 592-603, 2000. [2] D. Coniam, "Voice recognition software accuracy

[17] T. Chen, C. Huang, E. Chang, and J. Wang, "Automatic accent identification using gaussian mixture models," in Automatic Speech Recognition and Understanding, 2001. ASRU'01. IEEE Workshop on. IEEE, 2001, pp. 343-346. 